\section{Voluntariado e negociação de protocolos de vacinas anti-HIV no Brasil}

\author{
Volunteers and negotiation of anti-HIV \\ vaccine protocols in Brazil
}

\author{
1 Universidade Federal do \\ Rio de Janeiro, Rio de Janeiro, \\ Brasil. \\ 2 Instituto de Medicina \\ Social, Universidade do \\ Estado do Rio de Janeiro, Rio \\ de Janeiro, Brasil. \\ Correspondência \\ G. C. P. Cardoso \\ Universidade Federal do Rio \\ de Janeiro. \\ Rua Nascimento Bittencourt \\ 27, apto. 101, Rio de Janeiro, \\ RJ 22461-110, Brasil. \\ gisela.cardoso@gmail.com
}

\section{Abstract}

This study monitored the protocol of a clinical trial for experimental anti-HIV vaccines in Rio de Janeiro, Brazil, focusing on the recruitment, selection, and follow-up of volunteers. The techniques included observation of the research center's routine and interviews with health professionals and volunteers. The results show that the trial is a collective activity, in which constant negotiations are needed between the protocol requirements and what can, should, or must be adapted in order for it to work, as a function of: prolonged time before the trial's approval by the regulatory bodies, difficulties in recruiting volunteers, and even larger problems like discontinuity in the vaccines (which occurred in a specific protocol). The article discusses how the protocol's application extends beyond the technical and scientific "script", transforming it into a boundary object between different social worlds. The protocol is adapted according to a local order, based on the dynamics of social relations and the constant interrelationship between science, society, technique, and politics.

AIDS Vaccines; Voluntary Programs; Clinical Trials as Topic; Acquired Immunodeficiency Syndrome
Gisela Cordeiro Pereira Cardoso 1 Marilena Cordeiro Dias Villela Corrêa 2
Desde a identificação do vírus da imunodeficiência humana (HIV) como agente etiológico da AIDS, em 1981, o desenvolvimento de uma vacina específica se tornou um imperativo ético face ao impacto da doença em nível global 1 . O Brasil sedia testes clínicos de medicamentos e ensaios com vacinas experimentais anti-HIV 2, integrando a rede de vacinas HVTN - HIV Vaccine Trials Network [Rede de Pesquisa de Vacinas anti-HIV] -, vinculada aos National Institutes of Health (NIH) dos Estados Unidos. Desde 2001, vacinas anti-HIV desenvolvidas por laboratórios farmacêuticos internacionais são testadas no Brasil. Mas a transformação da pesquisa em ações e bens de saúde é um processo complexo, árduo, dispendioso e demorado ${ }^{3}$.

Os ensaios vinculados à rede HVTN são de tipo multicêntrico, ou seja, conduzidos simultaneamente em diferentes lugares do mundo. Os resultados obtidos nos diferentes centros participantes devem ser harmonizados e, para isso, é importante contar com uma equipe profissional treinada segundo padrões internacionais conhecidos como "boas práticas clínicas" (do inglês, good clinical practice). Trata-se de um conjunto de normas operacionais para o planejamento, execução e acompanhamento da pesquisa visando à uniformização do ensaio nos diferentes centros. Exige-se uma infra-estrutura clínica e laboratorial para coleta de exames, armazena- 
mento de amostras e farmácia para manipulação dos produtos vacinais. Ao mesmo tempo, deve ser instalada uma estrutura organizacional de registro, organização e gerenciamento dos dados oriundos dos testes 4 . Entram em jogo, também, instâncias regulatórias, nacionais e internacionais, para avaliação de questões éticas relacionadas às pesquisas com seres humanos e controle do padrão de qualidade, em relação às condições locais de aplicação dos testes 5,6. Finalmente, as boas práticas clínicas incluem estratégias de captação e retenção de pacientes e voluntários dentro do protocolo clínico.

No Rio de Janeiro, centro de pesquisas ligado à Universidade Federal do Rio de Janeiro (UFRJ) é responsável pela execução de testes clínicos de vacinas experimentais anti-HIV e de drogas anti-retrovirais (ARV), desde 1995. Este artigo se origina de uma pesquisa realizada naquele sítio de testes clínicos que objetivou analisar as rotinas de recrutamento, seleção e seguimento de um grupo de voluntários de ensaio de vacinas. Pesquisa orientada, do ponto de vista teóricometodológico, pelos estudos sociais das ciências e das técnicas. Para os estudos sociais, a análise da associação entre aspectos de natureza diversa, tal como ocorrem nas práticas científicas, é central. Assim, falar do voluntariado nesse ensaio de vacinas implica incluir o mundo social dos participantes (voluntários e profissionais) naquele das práticas científicas altamente codificadas do estudo experimental e vice-versa; ou seja, implica identificar hibridizações entre esses mundos por meio da associação de elementos de um ou outro dos mundos que não podem ser considerados isoladamente.

\section{Situação na literatura}

Para a sociologia da inovação e os estudos sociais das ciências, os protocolos podem ser vistos como "scripts" técnico-científicos que especificam as ações a serem realizadas, o local de execução, os sujeitos envolvidos com suas respectivas motivações, aspirações e valores 7. Ao mesmo tempo em que prescreve o encontro entre voluntário e profissional de saúde ao padronizar "boas práticas" entre os atores e as intervenções a serem realizadas dentro de determinado espaço e tempo, o protocolo articula e delimita práticas de mundos sociais diferentes, agrupando pessoas com múltiplos referenciais de educação, financeiro, cultural, profissional num mesmo local e entre diferentes locais, quando se trata de estudos multicêntricos 8,9. A articulação entre "mundos sociais" diferentes seria facilitada por objetos denominados boundary objects (objetos fronteiriços), segundo essa tradição de estudos. Um objeto fronteiriço pode ter uma utilização rígida num determinado contexto e mais flexível em outro 9,10, em função de situações que se impõem no dia-a-dia, de diversas maneiras. Assim, adaptações precisam ser operadas, seja na linguagem utilizada na aplicação do protocolo, seja no respeito ou submissão aos prazos de comissões de ética ou ainda em procedimentos de recrutamento de voluntários, entre outros.

Designa-se "negociações" os acertos e arranjos feitos sucessivamente entre o que é exigido pelo protocolo em si e o que, de alguma maneira precisa, pode ou deve ser adaptado para que o mesmo funcione dentro do contexto local em que está sendo utilizado. Esta "ordem negociada" 11,12 dá visibilidade aos processos de associação entre diferentes saberes no manejo do protocolo clínico, como discutiremos neste artigo.

\section{Objeto e objetivos}

O objeto deste estudo foram as rotinas e os processos de recrutamento, seleção e seguimento dos voluntários de um teste de vacinas experimentais anti-HIV, de caráter multicêntrico - o HVTN 055 - conduzido no Projeto Praça Onze da UFRJ.

O estudo teve como objetivo responder questões sobre: (i) a organização de um ensaio clínico fase I, de vacinas experimentais anti-HIV; (ii) os significados da participação no ensaio e as motivações de tornar-se voluntário; e (iii) a forma como se negocia, incorpora e maneja o protocolo clínico em termos de ajustes e adaptações possíveis e necessárias entre profissional e voluntário.

\section{Metodologia e técnicas de investigação}

Para realizar o estudo, situamo-nos como observadora participante 13 , ao nos inserirmos dentro das rotinas do protocolo. Freqüentamos o local de testes três vezes por semana por um primeiro período de dez meses, e após quatro meses de interrupção da observação, retomamos a participação por mais um mês, por ocasião das consultas de encerramento do ensaio.

Desse modo, seguimos cotidianamente a rotina de marcação das visitas dos candidatos e voluntários para o ensaio HVTN 055, a fim de estarmos presentes nas diferentes consultas pelas quais o voluntário deveria passar: recrutadores, aconselhadores, equipe médica e de enfermagem. Utilizamos para registro um caderno de campo em que anotávamos o convívio na sala de espera, as interações entre candidatos, volun- 
tários e profissionais, a preparação dos produtos vacinais, a aplicação propriamente dita das vacinas, a realização de coletas de sangue e de eletrocardiogramas, além das consultas. Tivemos acesso também aos documentos e protocolos relacionados ao ensaio clínico, incluindo o termo de consentimento livre e esclarecido (TCLE), mas não obtivemos autorização para divulgá-lo. Após três meses de acompanhamento das rotinas, confeccionamos um roteiro de entrevistas semi-estruturadas que foram aplicadas aos 13 voluntários do protocolo HVTN 055. Em seguida, entrevistamos com instrumento semelhante 17 profissionais da Unidade de Avaliação de Vacinas (UAV) do Projeto Praça Onze.

Em etapa anterior, o estudo foi aprovado pelo Comitê de Ética em Pesquisa (CEP) do Hospital Universitário Clementino Fraga Filho da UFRJ. Todos os entrevistados assinaram o TCLE, no qual estão assegurados confidencialidade e anonimato das informações dadas.

\section{Terreno}

Criado em 1995, o centro de pesquisas clínicas conhecido como Projeto Praça Onze é amparado pela estrutura física da UFRJ. Encontra-se instalado no Hospital Escola São Francisco de Assis (HESFA), mesmo local do Centro de Testagem Anônima (CTA).

A arquitetura do HESFA é imponente, datando do século XIX, mas, apesar da importância, sua estrutura e conservação externa se encontram em situação precária. Ao entrarmos no centro de pesquisa, o contraste entre ele e seu entorno (o antigo hospital) é gritante. Mesmo não sendo luxuoso, o ambiente dentro do centro é claro, limpo e moderno.

No início de seu funcionamento, o projeto contava com uma equipe de 15 profissionais, a maioria oriunda da UFRJ. Aos poucos o centro foi se expandindo, captando recursos para a realização de testes de produtos vacinais e de medicamentos ARV. A estrutura organizacional foi-se tornando mais complexa, passando de um modelo de cunho mais acadêmico para outro de perfil mais empresarial. Atualmente, a equipe é formada por um híbrido de profissionais, com diferentes inserções contratuais: funcionários públicos federais (UFRJ), profissionais contratados, ativistas de organizações não-governamentais (ONG). Destaca-se que alguns - dois recrutadores e uma das aconselhadoras, juntamente com a coordenadora de educação comunitária - são oriundos de uma mesma ONG/AIDS, o Grupo Pela Vidda de Niterói, muito atuante no Estado do Rio de Janeiro e no Brasil.

\section{Estudo HVTN 055}

Em 2006, foi iniciado o estudo de fase I, cujo objetivo era avaliar a segurança e a imunogenicidade de uma nova vacina: duas baseadas em MVA (vaccinia vírus) e duas baseadas em FPW (fowlpox virus), sozinhas ou combinadas. As vacinas foram testadas em voluntários saudáveis, entre 18 e 25 anos, sem infecção pelo HIV e virgens de imunização pelo vírus da vaccinia. Além desses dois objetivos do estudo experimental, havia o interesse de se investigar também o impacto social da participação no ensaio na vida da pessoa.

No Rio de Janeiro, de uma projeção inicial de 20 voluntários, conseguiu-se recrutar 14 pessoas (menos uma desistência). Foram recrutados voluntários na cidade de São Paulo e, fora do Brasil, no Peru e Estados Unidos. Projetou-se um total de 150 participantes no estudo multicêntrico. Em novembro de 2006, com o ensaio em andamento, a aplicação de vacinas foi suspensa por orientação do HVTN. Esta orientação da rede mundial de vacinais seguiu-se a uma demanda oriunda do produtor da vacina, a firma Therion Biologics Corporation, em função de "desinteresse comercial”, como comunicado aos responsáveis locais.

Isso deixou cinco voluntários do projeto sem receber a última dose vacinal, dentre os quais um deixou de receber duas doses. Veremos os desdobramentos ocorridos.

\section{A trajetória de tornar-se voluntário}

O recrutamento e a seleção dos voluntários são realizados por uma equipe que integra quatro recrutadores e quatro aconselhadoras. Três aconselhadoras têm formação em psicologia e uma é assistente social. Entre os recrutadores, encontramos pessoas de diferentes formações. $\mathrm{O}$ fato de alguns recrutadores e aconselhadoras serem também militantes de ONG/AIDS faz que tenham grande experiência na utilização de recursos e técnicas de recepção e acolhimento de participantes em pesquisas no campo da AIDS.

Segundo eles, a estratégia de recrutamento mais produtiva em termos de retorno de candidatos envolve os meios de comunicação; especialmente quando se divulgam telefones de contato para que as pessoas possam ligar e obter as primeiras informações. São citadas também matérias de divulgação, em período mais recente, nas quais aparecem voluntários dando seu depoimento na grande mídia, como forma de sensibilizar a população. Outra estratégia de recrutamento passa pela mobilização do CTA, que funciona no primeiro andar do HESFA, logo abaixo das instalações do projeto. Um dos recrutadores 
e duas das aconselhadoras fazem parte das duas equipes de aconselhadores (do CTA e do Projeto Praça Onze), o que constitui um importante elo na absorção de candidatos a voluntários de testes clínicos de vacinas e medicamentos.

Após o primeiro contato telefônico, o candidato é convidado a comparecer ao projeto para uma entrevista com uma aconselhadora ou para assistir a uma palestra juntamente com outros candidatos

Passada essa porta de entrada do recrutamento, o voluntário segue para o Projeto Acolhimento (PAC), coordenado pelos recrutadores. São objetivos do PAC: (i) conhecer as características dos candidatos (faixa etária, renda, moradia, escolha sexual, vínculo empregatício); (ii) identificar as motivações para participação em ensaios clínicos experimentais; e, (iii) registrar como tomaram conhecimento dos estudos realizados no projeto.

Os critérios de elegibilidade para participação nos ensaios de vacinas são de diferentes ordens: clínicos/laboratoriais (em particular, sorologia negativa para o HIV e outras doenças sexualmente transmissíveis, motivação (consistente) e de comportamento (vida sexual e uso de álcool, drogas e tabaco). Outro dado fundamental é a disponibilidade de tempo para comparecer ao projeto no horário da manhã, com a freqüência exigida, durante período determinado. O grupo de potenciais voluntários vai, portanto, tornando-se restrito em função das inúmeras exigências impostas pelos protocolos. Para o HVTN 055, foram relatadas a nós dificuldades no recrutamento por conta da população requerida: pessoas de 18-25 anos, sem contato direto anterior com a AIDS; e pela pouca experiência dos recrutadores no contato com um grupo de tal perfil (estando estes muito mais familiarizados em recrutar homens que fazem sexo com homens).

A etapa seguinte ao PAC é a de screening. No estudo HVTN 055, o screening compreendeu duas visitas. Na visita 1, realizaram-se (i) duas entrevistas individuais - uma para leitura do TCLE feita por uma aconselhadora e, logo em seguida, uma entrevista de avaliação de compreensão e riscos, com uma segunda aconselhadora; (ii) consulta médica em que se inclui o histórico médico e exame físico; e, (iii) realização de exames laboratoriais (sangue e urina), além de um eletrocardiograma.

A leitura do TCLE marca a apresentação formal do voluntário ao protocolo experimental. A aconselhadora se detém cuidadosamente em várias partes do TCLE, lançando mão de desenhos (do HIV) e exemplos para auxiliá-la em suas explicações. Em um dos casos acompanhados, somente na leitura da página 1 do termo - onde constam o nome oficial do estudo (6 linhas) e seu título resumido (3 linhas) - a aconselhadora deteve-se por 35 minutos.

A primeira informação importante dada ao candidato é que o estudo no qual ele foi incluído como candidato tem três objetivos: avaliar a segurança (efeitos colaterais) e a imunogenicidade dos produtos vacinais testados assim como o estudo do impacto social.

Com relação ao último, a aconselhadora explicita que se trata de uma análise das possibilidades de discriminação social, problemas pessoais ou injustiças que possam surgir pelo fato de a pessoa ter participado no estudo experimental. A questão da confidencialidade - identificação da pessoa mediante um número - é enfatizada, pois além do interesse científico existe o senso ético de proteger o voluntário.

Caracteriza também, para o voluntário, o tipo de teste do qual ele participará como um ensaio clínico duplo-cego, em que uma metade dos voluntários toma o produto vacinal e a outra, uma substância inócua, chamada placebo, de modo a serem comparados os efeitos em ambos os grupos. Aborda o número esperado de participantes, a duração do estudo, os critérios de inclusão e de exclusão, as aplicações de injeções e as coletas de sangue.

A aconselhadora enfatiza que as vacinas em estudo não protegem contra o HIV, da possibilidade da resposta imunológica do organismo provocar um resultado positivo do teste anti-HIV, da necessidade de se afastar a possibilidade de gravidez e evitar o sexo desprotegido.

Reforça o papel da participação voluntária, da possibilidade de sair do estudo sem sofrer penalidade, e do não-pagamento ao voluntário, o que representa o compromisso do participante com o estudo, e também está em acordo com as normas regulamentadoras da Comissão Nacional de Ética em Pesquisa (CONEP) para participação de pessoas em pesquisas no país.

A todo o momento, pergunta-se ao candidato se ele entende o que está sendo dito e se precisa de mais esclarecimentos. O volume de informações é enorme e nos perguntamos se é possível que o candidato entenda tudo aquilo, por mais cuidadosa que seja a abordagem da aconselhadora em termos de adequação de linguagem e repetição das informações.

Como dito, a 2a entrevista de screening é realizada logo a seguir, por outra aconselhadora. Essa entrevista de avaliação de compreensão e de riscos visa checar possíveis dúvidas por meio de um formulário com perguntas do tipo verdadeiro ou falso. Neste segundo momento, é realizada também uma avaliação, em formulário especifico, dos riscos ligados à vida sexual que procura 
explorar o número de parceiros/as sexuais nos últimos seis meses, o conhecimento do estado sorológico para o HIV dos diferentes parceiros/ as e os tipos de práticas sexuais, além do uso de álcool, drogas, entre outros. Essas perguntas configuram uma "invasão de privacidade" na vida afetiva e sexual do candidato que, ao aceitar responder à entrevista, assume estar disposto a se submeter a tal "invasão". Sua vida fica devassada sob todos os aspectos, pelas perguntas e exames laboratoriais, partes integrantes do pacote tornar-se voluntário. Embora as questões colocadas objetivem apenas caracterizar o candidato como "um bom voluntário", sem qualquer julgamento moral pressuposto, a produção de certo mal-estar é visível em casos individuais. Uma vez aprovado, a aconselhadora registra no prontuário: elegivel pelos critérios comportamentais.

Após essas duas entrevistas de screening, o candidato é chamado para a consulta médica que inclui anamnese minuciosa, exame físico, coleta de exames laboratoriais, testes anti-HIV, anti-HBC e eletrocardiograma. Ao final do processo, o recrutador agenda o retorno do candidato, em um prazo que variou de 7 a 56 dias. No retorno, o candidato é informado por uma das aconselhadoras sobre os resultados dos exames e se poderá ser incluído no ensaio clínico.

Para o estudo HVTN 055, previa-se um total de 13 visitas para cada voluntário, sendo cinco de vacinação - as visitas 2, 4, 6, 8 e 10 - e as visitas de pós-vacinação, que ocorrem aproximadamente 14 dias após a aplicação da vacina - visitas de números 3, 5, 7, 9 e 11. As seguintes, visitas $12 \mathrm{e}$ 13 são de acompanhamento clínico. Terminada a etapa de vacinação, ocorre uma última visita para revelação de código. É neste ponto que o voluntário (bem como o responsável pelo protocolo) toma conhecimento do grupo no qual foi aleatoriamente alocado durante o procedimento de cegamento, vale dizer, se tomou o produto vacinal ou placebo.

\section{A aplicação da vacina}

A rotina das diferentes consultas é praticamente a mesma: o voluntário é recebido pela recepcionista, que avisa a enfermeira de sua chegada para que ela desarquive o prontuário do voluntário e verifique os procedimentos a serem realizados naquele dia, de acordo com o número da visita.

A la consulta do dia é sempre com a aconselhadora, que checa as informações cadastrais, faz um resumo da visita anterior ao centro e realiza nova avaliação de riscos, assim como coleta informações sobre o impacto do estudo na vida da pessoa. Após a consulta com a aconselhadora, o voluntário segue para a avaliação médica, na qual são feitos exames clínicos e físicos. O médico segue sempre o mesmo roteiro: verifica a pressão arterial, pesa e mede, além de checar se entre uma consulta médica e outra o voluntário fez uso de alguma medicação ou de outra vacina. Em visitas intercaladas são coletados exames de sangue e de urina, além de ser feito um eletrocardiograma. Antes de ir embora, o voluntário é atendido novamente pela enfermeira, que lhe transmite as últimas orientações e o encaminha para o recrutador, responsável pelo agendamento da próxima visita. Por fim, retorna à recepcionista, que lhe entrega o dinheiro do transporte e os preservativos antes de sua saída do centro. Essa seqüência de consultas dura entre duas e três horas, sendo maior nos dias de aplicação da vacina em função do tempo de preparo do produto vacinal. Se voluntária mulher, acresce-se ainda o tempo de realização do exame beta-HCG e seu resultado para identificação de gravidez.

Todos os profissionais envolvidos no ensaio clínico têm funções que são específicas de sua formação e outras compartilhadas com os demais membros da equipe, em uma verdadeira hibridização das práticas. Algumas recomendações são inúmeras vezes repetidas pelos diferentes profissionais: "Isso é uma coisa que vamos sempre estar perguntando... Faz parte do protocolo, acompanhar e reforçar as práticas de sexo seguro". Essas intervenções objetivam uma gestão racional de possíveis riscos de diferente natureza, não só sexuais, mas também dos efeitos das vacinas no organismo, do impacto social na vida do voluntário e no que se refere à adesão ao protocolo clínico. Isto é feito por meio de um trabalho retórico coletivo, na tentativa de a equipe obter uma resposta do candidato que possa ser consistente conforme exigido no protocolo.

Nesse gerenciamento, a enfermagem e os médicos orientam constantemente o voluntário para ficar atento aos horários das ligações telefônicas, feitas pela equipe, para checar, por exemplo, sua temperatura e preencher o manual de pós-vacinação, entre outros, envolvendo ativamente o voluntário na gestão dos riscos 14 .

O universo do experimento vai, assim, expandindo-se para o universo cotidiano do voluntário, que passa a incorporar em sua rotina práticas trazidas do centro de pesquisas. Ele próprio começa a manejar e interpretar dados de seu corpo dentro de um saber especializado, e não apenas em seu contexto leigo usual ${ }^{15}$. Ocorre, nesse processo, uma “colonização" do saber leigo pelo saber especializado, por intermédio de uma crescente permeabilidade dos universos leigos à apropriação e incorporação de referências do universo científico, assimiladas no contato com 
os profissionais de saúde, como identificado, a seguir: "A partir de hoje, durante três dias, vou te ligar algumas vezes por dia. Você vai ter que tirar a temperatura às dez para três da tarde porque eu vou te ligar às três [mostra o espaço no manual onde tem que registrar a temperatura]. Isso vai ocorrer de manhã e de noite também, tá?".

O ensaio clínico exerce uma relação de vigilância das práticas cotidianas do voluntário e controle sobre seu corpo. Ao mesmo tempo em que o voluntário rompe com inúmeras barreiras - em particular do medo e do preconceito para participar do ensaio clínico, ele se sujeita a ser um indivíduo sob "controle". Nesta situação ambígua e contraditória, posiciona-se, submetendo-se, porém, às normas do ensaio clínico (e, em última instância, às das ciências biomédicas); "sujeita-se" a essas normas em nome de uma vontade: tornar-se coadjuvante da invenção de uma nova ferramenta biotecnológica: "Participar do processo é emocionante... funcionou porque eu estava lá".

No mundo contemporâneo, o saber da ciência é altamente valorizado (inclusive do ponto de vista do investimento financeiro na pesquisa), ocupando um espaço de verdade na resolução dos problemas, como pode ser a descoberta da cura da AIDS. Nesse contexto, a motivação para tornar-se voluntário de um ensaio de vacinas pode estar relacionada ao lugar ocupado pelo discurso científico na sociedade contemporânea, independentemente dos níveis de envolvimento identificados com a questão da AIDS. No HVTN 055, este envolvimento variou desde um nível mais direto (o voluntário sentindo que poderia ser atingido pelo HIV), passando por outro relativamente próximo (pessoas amigas, ex-parceiros e/ou familiares afetados), até um nível mais distante, segundo os relatos coletados: "Pensei no meu irmão soropositivo", "Você está numa luta político-social, isso faz de você uma pessoa diferente", "Ajudar me faz bem”, "Contribuir para a ciência é algo muito bem visto na minha cabeça”.

Logo, tornar-se voluntário envolve uma trajetória biopolítica - posicionar-se como querendo e se qualificando ao papel de voluntário; e uma bioidentidade, na entrega do próprio corpo à medicina, lugar de exercício daquele papel 16. O biológico, entrando no campo do saber, refletese no político pelo poder representado pela intervenção das ciências biomédicas.

\section{Surpresa no protocolo experimental: interrupção das vacinações}

Em novembro de 2006, o Projeto Praça Onze recebeu a orientação do HVTN de suspender as vacinações do estudo 055 em razão de "problemas administrativos” com o laboratório fabricante dos produtos vacinais, Therion Biologics Corporation. Apesar de a interrupção estar prevista como possibilidade no texto do TCLE, podendo ser acionada pela FDA (U.S. Food and Drug Administration), pelo NIH, pelo fabricante de vacina que patrocina o estudo, pelo CEP ou pela CONEP, isto não é algo esperado, nem pela equipe, nem pelo voluntário. De fato, a interrupção das vacinações foi motivo de grande comoção dentro do projeto, gerando preocupação na equipe em relação ao impacto que uma notícia como esta poderia ter nos voluntários, na instituição e na comunidade científica em geral.

Seguindo orientações da coordenação geral, a equipe se organizou para transmitir essa informação aos voluntários da forma mais clara possível. A maioria dos profissionais relatou extrema dificuldade na comunicação da notícia Para surpresa da equipe, a maioria dos voluntários pareceu aceitar a explicação transmitida pelas aconselhadoras, ainda que manifestasse sua decepção com o ocorrido. Para um dos recrutadores, a reação de "aceitação" seria explicada pelo fato de a maior parte das doses de vacinas já terem sido aplicadas (seis voluntários ficaram sem completar as vacinações) e também porque, segundo esse recrutador, todos os voluntários deste estudo já haviam construído uma relação sólida e de confiança com a equipe do projeto. O respaldo da UFRJ, como instituição, também teria ajudado a sustentar a credibilidade, como evidencia a fala do voluntário: "Eu confiei no estudo e no que me cercava, a instituição". Outra, contudo, comentou conosco: "Me sinto muito frustrada... deve ter sido um grande rombo mesmo!", expressando sua sensação de ter sido lesada em seus sonhos e expectativas.

Apesar de tratar-se de um estudo de fase I, o grau de investimento de profissionais e voluntários é muito alto. Para os últimos, ajudar, ser útil doando seu corpo, seu tempo, sua disposição é algo fundamental, que passa a fazer parte de sua vida. Ele está comprometido afetivamente sempre e, na maioria das vezes, ideologicamente também. Já o profissional investe seu conhecimento e tempo por acreditar que mais cedo ou mais tarde se conseguirá desenvolver uma vacina eficaz contra a AIDS. Do mesmo modo como o voluntário enfrenta sua família, seus amigos, o profissional muitas vezes tem que enfrentar seus colegas, os comitês de ética em suas múltiplas 
instâncias e mesmo ONG; todos atores implicados em associação na pesquisa e desenvolvimento de uma nova tecnologia na área biomédica 17,18,19,20.

Face à interrupção das vacinações, ficam perguntas: Qual é o valor do protocolo HVTN 055? Qual é o sentido do tornar-se voluntário nesse contexto? Questiona-se também: e se os voluntários tivessem se recusado a assinar o adendo ao TCLE, o que teria ocorrido? Ademais, chama atenção o fato de, apesar de vários membros da equipe pertencerem a uma ONG/AIDS, não ter havido nenhuma mobilização ou repercussão da interrupção das vacinações fora do espaço do projeto. Isso reforça o enorme controle exercido pelas instâncias patrocinadoras e financiadoras em relação aos direitos e ao destino dos voluntários de ensaios clínicos 21. Apenas um voluntário manifestou: "Eu menti para minha família e disse que tinha tomado a última dose porque se eu fosse dizer o que tinha acontecido pra eles, aí é que iam dizer mesmo que não era uma coisa séria".

Fica evidente como o poder das biotecnologias, organizadas de forma industrial no capitalismo contemporâneo, é altamente centralizador e excludente, tornando a vida despojada de qualquer singularidade 22. A interrupção "administrativa” do ensaio - leia-se, alegação de desinteresse comercial no produto em teste - expressa vivamente a perspectiva do fazer científico que objetiva o lugar desse ator central que é o voluntário, bem como o de outras pessoas envolvidas, como representantes de associação de pacientes, profissionais de saúde, formuladores de políticas, entre outros.

\section{Revelação de código na visita pós-estudo}

Após a visita 13, considerada a última do ensaio, o voluntário é chamado para retornar ao Centro de pesquisa para a visita de pós-estudo ou visita de revelação de código, quando o profissional e o voluntário tomam conhecimento de quem recebeu o produto vacinal e quem ficou no grupo placebo. A etapa de revelação de código é sincronizada com o término dos ensaios nos demais centros participantes do estudo multicêntrico.

Paralelamente à interrupção do HVTN 055, outro ensaio vacinal multicêntrico conduzido no projeto, o HVTN 502 foi igualmente interrompido (em todos os centros onde vinha sendo conduzido). Neste segundo caso, a interrupção se deu por razões de segurança: a resposta imunológica à vacina não estava se mostrando efetiva para prevenir a infecção pelo HIV ou reduzir a carga viral nos indivíduos infectados. Trazemos esse segundo caso aqui porque o projeto recebeu orientação do HVTN para que antes da revelação de código aos voluntários do aqui analisado, os voluntários de todos os ensaios em andamento no centro fossem informados a respeito da interrupção do HVTN 502. Assim, os voluntários do HVTN 055 foram chamados para receber simultaneamente a revelação de código do estudo do qual participaram (e que havia sido interrompido por razões administrativas) e as explicações da interrupção do HVTN 502; primeiramente de forma verbal e posteriormente via carta postada no correio.

Observamos seis dentre as treze consultas de revelação de código. A cada vez a aconselhadora começava a entrevista de maneira diferente, tentando "adaptar" o que estava fora do previsto: o anúncio da interrupção do protocolo de vacinação de outro estudo, HVTN 502. Uma voluntária comentou: "É complicado porque é tanta informação... Não dá nem pra perguntar nada”.

Após a revelação de código, as recomendações variavam. Para os voluntários que receberam o produto vacinal e obtiveram algum tipo de resposta imunológica, a conduta clínica era de mantê-lo em acompanhamento no projeto até que a sorologia para o HIV volte a ser negativa. Os voluntários que tomaram o produto vacinal e não apresentaram resposta imunológica foram liberados e desaconselhados de participar de outras pesquisas de vacinas, para não ficarem submetidos a novos produtos experimentais. Já os voluntários que tomaram placebo eram liberados tanto para a realização de exames fora do projeto quanto para a participação de outros ensaios clínicos.

A fala do seguinte voluntário que havia tomado placebo revela as reconstruções da motivação para o voluntariado "Para mim não faz muita diferença..., o importante é estar contribuindo”; no que é reforçado pela aconselhadora: "Tão importante quanto tomar a vacina é tomar o placebo porque o importante é a comparação. Sua participação é fundamental...”. Vemos mais uma vez os valores da ciência sendo incorporados pelo voluntário. Na medida em que participa do ensaio clínico, ele é um parceiro privilegiado no processo experimental, sujeitando-se e identificando-se com os mecanismos da ciência que caracterizam a forma dominante de exercício contemporâneo do (bio)poder 16 .

A aplicação do protocolo transborda, portanto, o script técnico-científico, criando uma nova ordem, de acordo com o local onde é realizado. O protocolo, enquanto objeto fronteiriço, será sempre interpretado e manejado de maneira particular, pontuada pela dinâmica das relações profissionais e sociais do espaço estrutural e ins- 
titucional em que está inserido e do contexto sócio-político local.

\section{Considerações finais}

As estratégias de recrutamento para ensaios em seres humanos realizados no Projeto Praça On$z e$ se sustentam primordialmente sobre a abordagem direta com o candidato a voluntário. Em nosso contexto, desde o início do processo é necessário um contato pessoal próximo, no qual se dá a interação entre profissional e candidato para a obtenção de informações e esclarecimentos. Isso difere das estratégias empregadas em outros locais, como a França, por exemplo, onde boa parte do processo ocorre mediante o preenchimento de formulários ("dossier de candidature") e termos de consentimentos, que são sempre enviados aos candidatos por correio, retornando pela mesma via à agência pública francesa coordenadora dos ensaios com vacinas anti-HIV 23,24. Tais diferentes abordagens indicam, mais do que uma diferença econômica, uma diferença de ordem sócio-cultural no estabelecimento de vínculos e no manejo das relações entre os indivíduos, à medida que no Rio de Janeiro o contato pessoal desde o início do processo de recrutamento parece ser fundamental, o que é verdade também para a adesão do voluntário ao ensaio clínico e sua finalização.

A construção da disposição para tornar-se voluntário é bastante abrangente e complexa, não podendo ser reduzida a um único fator 25 , variando desde um envolvimento de ordem pessoal e/ou profissional com pessoas com HIV/ AIDS, passando por posicionamentos políticos e ideológicos, incluindo também a influência da instituição que promove e realiza o ensaio clínico. Tornar-se voluntário é um processo - para alguns, rápido, para outros, mais lento - de construção de uma trajetória de sentido para essa nova experiência na vida do indivíduo. Nessa trajetória, não podemos desconsiderar o lugar ocupado pelo discurso das ciências biomédicas, altamente valorizado na resolução de diferentes tipos de problemas 26 e capazes de movimentar, igualmente, um importante capital financeiro. Tornar-se voluntário de um ensaio clínico não pode, assim, ser descontextualizado do meio sócio-político em que se está inserido, marcado pela biopolítica que integra de forma central a ordem social e econômica vigente.

Vimos também, que o papel das ONG vinculadas aos ensaios clínicos de vacinas anti-HIV/ AIDS no Rio de Janeiro se caracteriza como uma parceria que envolve incorporação e hibridização de conhecimentos e práticas. O ativista de ONG/AIDS inserido no centro de pesquisa torna-se um membro da equipe de saúde, não só por instrumentalizar os demais profissionais para lidar com grupos sociais mais vulneráveis ao HIV, mas também por incorporar do universo científico conhecimentos úteis para o recrutamento e seleção dos voluntários. Ao se fusionar com os profissionais de saúde, o representante da ONG passa a ser um deles, perdendo seu caráter contestador e provocador, ligado ao ativismo. A submissão ao protocolo, amparado pela força do discurso técnico-científico, passa a ser o novo eixo de posicionamento, distanciando-se de seu papel originário.

A produção do conhecimento científico inovador nos confronta inevitavelmente com situações paradoxais, tanto de libertação quanto de subjugação dos conhecimentos e práticas às normas econômicas e políticas da sociedade em que estamos inseridos. Na aplicação do protocolo clínico, objeto fronteiriço entre universos e interesses diversos, é fundamental que se leve em consideração o coletivo concreto que associa voluntários e pesquisadores do centro de pesquisa, instituindo-se um mínimo denominador comum do ponto de vista ético: o respeito à singularidade e ao comprometimento afetivo-ideológico dos sujeitos envolvidos do centro de pesquisa, que permita, nos casos em que não haja riscos à saúde dos voluntários do ensaio clínico, garantir a conclusão do estudo até seu final ${ }^{8}$. Só assim o avanço técnico-científico poderá estar em consonância com o estabelecimento de relações de maior simetria e igualdade entre as diferentes instâncias e atores que participam de ensaios clínicos, em nível nacional e internacional. 


\section{Resumo}

O estudo acompanhou a rotina de um ensaio clínico de vacinas experimentais anti-HIV no Rio de Janeiro, Brasil, focalizando os processos de recrutamento, seleção e seguimento dos voluntários. Utilizaram-se técnicas de observação da rotina do centro de pesquisas e entrevistas a profissionais e voluntários. Os resultados evidenciaram que o ensaio é uma atividade coletiva, em que constantes negociações são necessárias entre o que é exigido pelo protocolo e o que precisa, pode ou deve ser adaptado para que ele funcione, em função de situações como: tempo prolongado de aprovação do estudo pelas instâncias regulatórias, dificuldades no recrutamento de voluntários, até problemas maiores como a descontinuidade das vacinações (ocorrida no protocolo estudado). Discute-se como a aplicação do protocolo transborda o script técnico-científico, transformandose em um objeto fronteiriço entre mundos sociais diferentes. O protocolo é adaptado segundo uma ordem local, de acordo com a dinâmica das relações sociais, não podendo desconsiderar-se a constante inter-relação entre ciência, sociedade, técnica e política.

Vacinas contra AIDS; Programas Voluntários; Ensaios Clínicos como Assunto; Síndrome de Imunodeficiência Adquirida

\section{Referências}

1. United Nations. UN millennium development goals, 2002. http://www.un.org/milleniumgoals (acessado em Ago/2006).

2. Ministério da Saúde. Plano nacional de vacinas anti-HIV: pesquisa, desenvolvimento e avaliação. Brasília: Ministério da Saúde; 2002.

3. Morel CM. A pesquisa em saúde e os objetivos do milênio: desafios e oportunidades globais, soluções e políticas nacionais. Ciênc Saúde Coletiva 2004; 9:261-70.

4. Bastos FI, Hacker MA. Pesquisas brasileiras psicossociais e operacionais face às metas da UNGASS. Rev Saúde Pública 2006; 40 Suppl:42-51.

5. Programa Nacional de DST e AIDS. Relatório final. In: Seminário Internacional de Pesquisa em Vacina Anti-HIV. Questões Éticas e Regulatórias, 2006. http://www.aids.gov.br/data/documents (acessado em Jan/2008).

6. Cambrosio A, Keating P, Schlich T, Weisz G. Regulatory objectivity and the generation and management of evidence in medicine. Soc Sci Med 2006; 63:189-99.

\section{Colaboradores}

G. C. P. Cardoso planejou o estudo, realizou a coleta e análise dos dados. M. C. D. V. Corrêa participou do planejamento e da análise dos dados. Ambas trabalharam juntas em todas as etapas de elaboração do artigo.

\section{Agradecimentos}

Ao Programa Nacional de DST/AIDS por ter financiado parte da pesquisa, aos profissionais e voluntários do Projeto Praça Onze, por sua generosa colaboração e à Maria Andréa Loyola, por seus comentários e observações ao longo de realização do estudo.
7. Timmermans S, Berg M. The gold standard. Philadelphia: Temple University Press; 2003.

8. Tournay V. La gouvernnance des innovations medicales. Paris: Presses Universitaires de France; 2007.

9. Lowy I. La standardization de l'inconnu: les protocols thérapeuthiques en cancérologie. Technique \& Culture 1995; 2526:73-108.

10. Star SL, Griesemer JR. Institutional ecology, "translations" and boundary objects: amateurs and professionals in Berkeley's Museum of Invertebrate Zoology: 1907-39. Social Studies of Science 1989; 19:387-420.

11. Strauss A. La trame de la negotiation: sociologie qualitative et interactionisme. Paris: L'Harmattan; 1992.

12. Baszanger I. Les chantiers d'un interactionniste américain. In: Strauss A, editor. La trame de la negotiation. Paris: L'Harmattan; 1992. p. 11-63.

13. Minayo MC. Ciência, técnica e arte: o desafio da pesquisa social. In: Minayo MC, organizadora. Pesquisa social: teoria, método e criatividade. Petrópolis: Editora Vozes; 1995. p. 9-30. 
14. Spink MJ. Trópicos do discurso sobre risco: riscoaventura como metáfora na modernidade tardia. Cad Saúde Pública 2001; 17:1277-311.

15. Hess V. Standardizing body temperature: quantification in hospitals and daily life, 1850-1900. In Jorland G, Opinel A, Weisz G, editors. Body counts: medical quantification in historical and sociological perspectives. Montreal: McGill-Queen's University Press, 2005. p. 109-26.

16. Foucault M. Segurança, território, população. São Paulo: Editora Martins Fontes; 2008.

17. Barbot J. Les malades en mouvements. Paris: Balland; 2002.

18. Teixeira MO. As ciências sociais entre biólogos e vacinas: agruras do estudo de um laboratório. Hist Ciênc Saúde-Manguinhos 2004; 11:159-72.

19. Dodier N. Leçons politiques de l'épidémie de sida. Paris. Editions de l'EHESS; 2003.

20. Corrêa MCDV, Cassier M. Scaling up and reverse engineering. Acquisition of industrial knowledge by copying drugs in Brazil. In: Coriat B, editor. The political economy of HIV/AIDS in developing countries. The impacts of TRIPS on public health in the south. London: Edward Elgar; 2008; p. 130-49.
21. Oliveira MA, Santos EM, Mello JMC. AIDS, ativismo e regulação de ensaios clínicos no Brasil: o Protocolo 028. Cad Saúde Pública 2001; 17:863-75.

22. Rotania AA. Das Bios: a radical-idade. In: Rotania AA, Werneck J, organizadoras. Sob o signo das Bios: vozes críticas da sociedade civil. v. 1: reflexões no Brasil. Rio de Janeiro: E-papers Serviços Editoriais; 2004; p. 15-28.

23. Agence Nationale de Recherche sur le SIDA. Le recherche vaccinale contre le VIH à l'ANRS. Paris: Agence Nationale de Recherche sur le SIDA; 2003.

24. Cardoso GCP. Ensaios clínicos com vacinas antiHIV/AIDS: a rotina de incorporação de uma prática científica [Tese de Doutorado]. Rio de Janeiro Instituto de Medicina Social, Universidade do Estado do Rio de Janeiro; 2008.

25. Epstein S. Impure science. Berkeley/Los Angeles: University of California Press; 1996.

26. Laplante J, Bruneau J. Aperçu d'une anthropologie du vaccin: regards sus l'ethique d'une pratique humanitaire. Hist Ciênc Saúde-Manguinhos 2003; 10 Suppl 2:519-36.

Recebido em 15/Dez/2009

Versão final reapresentada em 28/Fev/2010

Aprovado em 03/Mai/2010 